\title{
Construction of 3D Digitizing Data Using Aerial Photographs Acquired by UAV
}

\author{
Keun-Wang Lee ${ }^{1}$ and Joon-Kyu Park ${ }^{2 *}$ \\ ${ }^{1}$ Department of the Multimedia Science, Chungwoon University, \\ 113, Sukgol-ro, Nam-gu, Incheon, Korea \\ ${ }^{2}$ Department of Civil Engneering, Seoil University, \\ 28, Yongmasan-ro 90-gil, Jungnang-gu, Seoul, Korea \\ ${ }^{1}$ kwlee@chungwoon.ac.kr, ${ }^{2} j k p a r k @ s e o i l . a c . k r$
}

\begin{abstract}
In recent years, the commercial development of Unmanned Aerial Vehicles (UAVs) become more prominent than their military purpose, which was where they originated, and this has expanded to various industries such as video capturing, disaster monitoring, agriculture, logistics, and broadcasting in the private market. The global market of UAV is expected to grow from about $\$ 5.2$ billion in 2010 to about $\$ 11.4$ billion by 2022, with the commercial market expected to grow at an annual rate of over $14 \%$ per annum by 2018. Although various studies related to UAVs have been performed, there remains a lack of research on the $3 D$ digitizing of results. Therefore, this study performs $3 D$ digitizing and volume calculation using UAV data. Digital Surface Models (DSM) and ortho images of a $300 \times 300 \mathrm{~m}$ area were generated through data acquisition for about 20 minutes and $3 D$ digitizing and volume calculation were performed with the results. $3 D$ digitizing data using UAV is compatible with software widely used in civil engineering fields such as CAD, so it is very useful and can be used for mapping because it is possible to classify layers; volume calculations using DSM data can greatly improve the efficiency of estimating earth work, because the quantity of fill and cut can be calculated through setting the reference plane.
\end{abstract}

Keywords: 3D digitizing data, Aerial photograph, Digital Surface Model, Geospatial information, $U A V$

\section{Introduction}

Unmanned Aerial Vehicle (UAV) is a system in which a pilot does not fly an aircraft directly, but instead remotely controls it from the ground or either autonomously or semi automatically in accordance with pre-programmed routes, or with artificial intelligence assistance and the whole system of GCS, communication equipment, and supporting equipment [1-3]. In recent years, the commercial development of UAVs has become more prominent than their military purpose, which is where UAVs originated, and their use has expanded to various industries such as video capturing, disaster monitoring, agriculture, logistics and broadcasting in the private market [4-6]. The global market of UAV is expected to grow from about $\$ 5.2$ billion in 2010 to about $\$ 11.4$ billion by 2022 , with the commercial market expected to grow at an annual rate of over $14 \%$ per annum by 2018 [7-9]. The domestic UAV market, with the global growth of the commercial UAV market, is rapidly growing at more than three times the rate of the previous year [10-12]. UAVs in the field of spatial information have attracted much attention in terms of the speed and economics of data acquisition, and various studies have been conducted [13-

Received (October 9, 2017), Review Result (December 19, 2017), Accepted (January 23, 2018)

*Corresponding author. 
15]. Acquiring 3D geospatial information such as point cloud data, Digital Elevation Models (DEM), and ortho images from images taken from a UAV, GPS surveying performance and comparative analysis were performed to analyze the accuracy of acquired data. In addition, a method of acquiring the latest geospatial information about a civil engineering construction site using unmanned aerial vehicle has been suggested and a method to support field management and rapid decision making using 3D geospatial information has been proposed [16-18]. Although there have been various studies on UAVs, there is a lack of research that directly generates 3D digitizing data using UAV data. This study performed 3D digitizing using UAV-acquired data. A UAV was used to capture the study area, and Digital Surface Models (DSM) and ortho images were generated through data processing, and 3D digitizing and volume calculations were performed using the results.

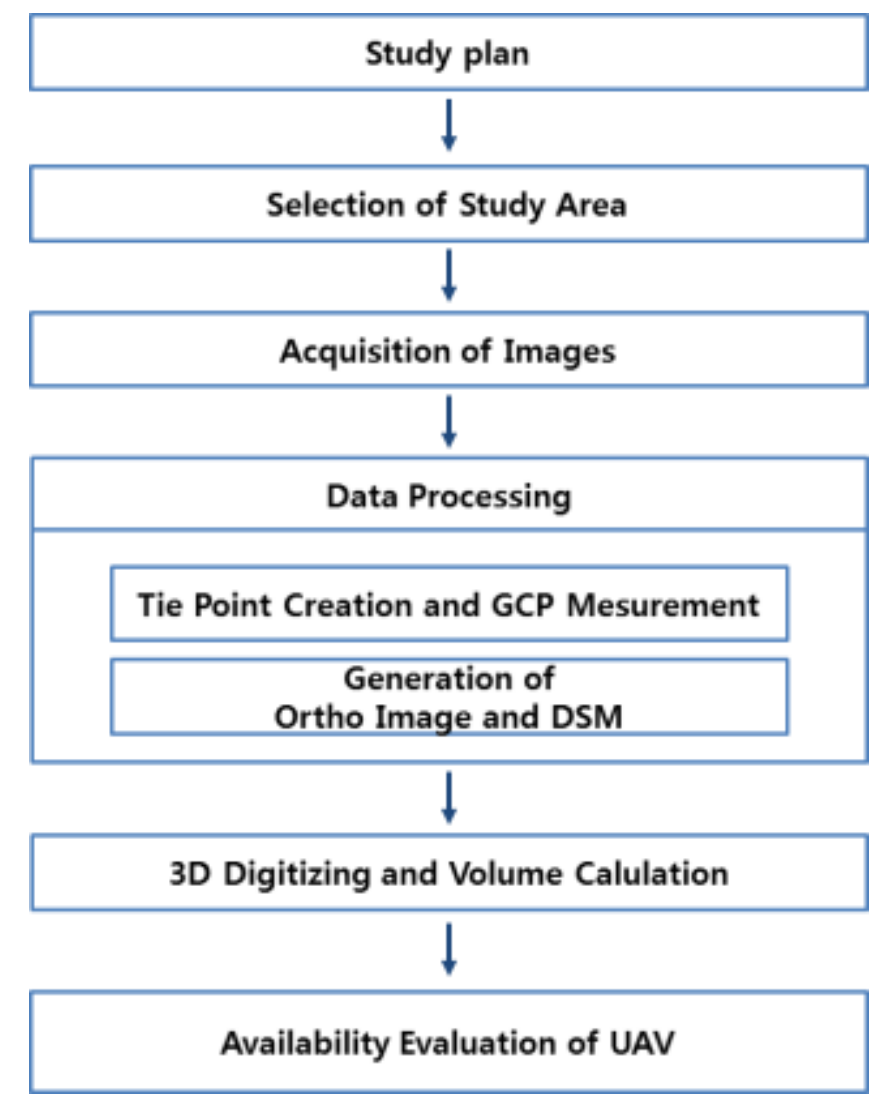

Figure 1. Study Flow

\section{Study Area and Image Acquisition}

Wonju city, which is the study site is developing a "Wonju Enterprise City"; this project started in 2005 with the concept of "the best advanced and advanced biomedical city" with the theme of Wonju city, "safe and convenient healthy city, rich life cultural city, and beautiful environmentally friendly ecological city" [18]. There are various buildings in the study area, and it is necessary to calculate volume due to civil works currently in progress. Therefore, we selected Wonju enterprise city as our study area. Figure 2 shows location of Wonju. 


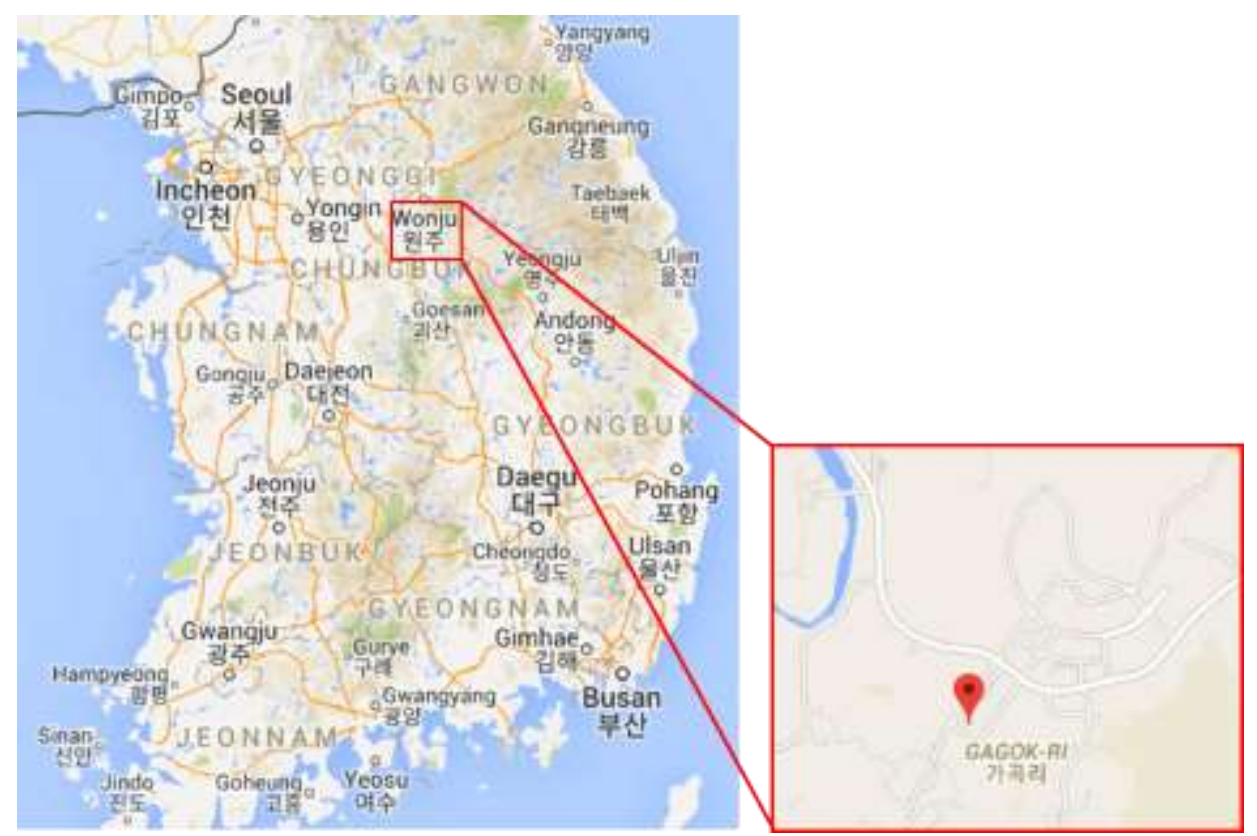

Figure 2. Location of Wonju

Aerial photographs were taken using a Phantom4 pro UAV in the study area. The photographing area was set to $300 \times 300 \mathrm{~m}$ for $3 \mathrm{D}$ digitizing and volume calculation, and data was acquired over approximately 20 minutes. Oblique photography was also performed for the 3D digitizing data of building. The Phantom4 pro model supports waypoint function and can perform aerial photogrammetry using GCP. Table 1 shows the specifications of the Phantom4 pro, and Figure 3 shows the Phantom4 pro.

Table 1. Specification of Phantom4 Pro

\begin{tabular}{|c|c|}
\hline Weight & $1.4 \mathrm{~kg}$ \\
\hline Flight Time & $30 \mathrm{~min}$ \\
\hline Size & $350 \mathrm{~mm}$ \\
\hline FOV (Field of View) & $84^{\circ}$ \\
\hline Camera Resolution & $20 \mathrm{MP}$ \\
\hline
\end{tabular}

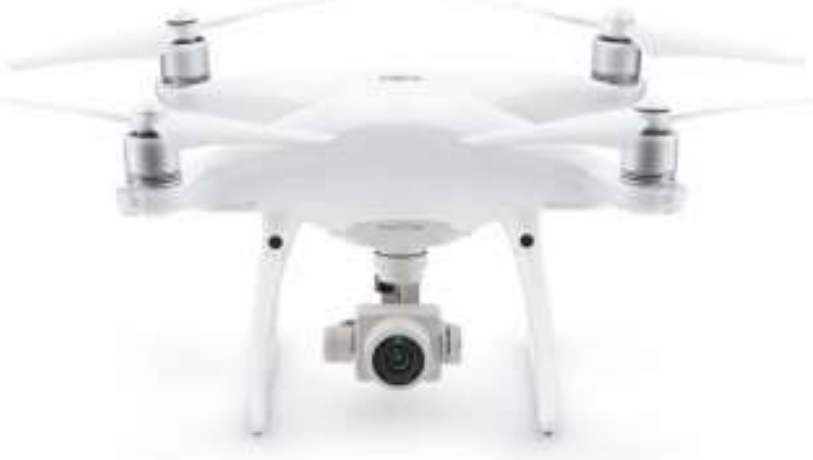

Figure 3. Phantom4 Pro

The flight plan was created using the Android application and we used three Ground Control Points (GCP) to improve the collected data's accuracy. The GCP survey was 
conducted using the VRS method, the GCP survey results are as shown in Table 2, and Figure 4 shows the Android application.

Table 2. GCP Survey Results

\begin{tabular}{|c|c|c|c|}
\hline ID & $\mathrm{N}(\mathrm{m})$ & $\mathrm{E}(\mathrm{m})$ & $\mathrm{H}(\mathrm{m})$ \\
\hline GCP01 & 427893.009 & 238226.226 & 44.928 \\
\hline GCP02 & 427986.471 & 238431.064 & 40.058 \\
\hline GCP03 & 427993.794 & 238140.826 & 37.479 \\
\hline
\end{tabular}

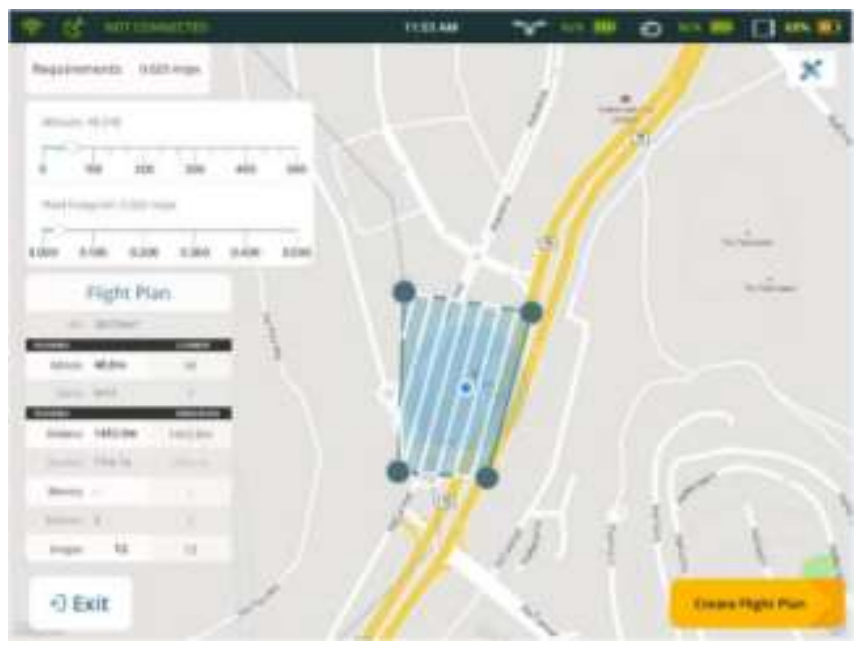

Figure 4. Android Application

\section{Data Processing}

The data collected by UAV consists of photographs taken and each photograph's Exterior Orientation (EO). In this study, photographs and EO values were used for UAV data processing. Phantom4 Pro stores geotagged photos, which allows this value to be used for data processing. Figure 5 shows the EO value of the geotagged photograph.
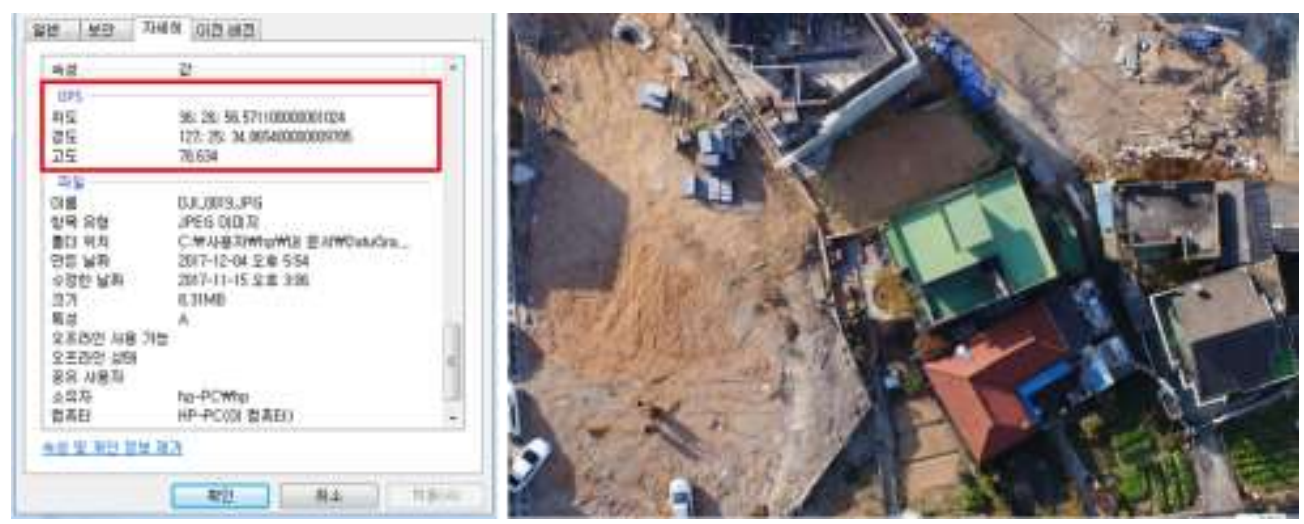

Figure 5. EO Value of the Geotagged Photograph

Datumate Software can create DSM and ortho images through UAV data processing. In addition, the software can perform 3D digitizing using the processing results and calculate the volume. The data processing process consists of five steps as shown in Figure 6. 


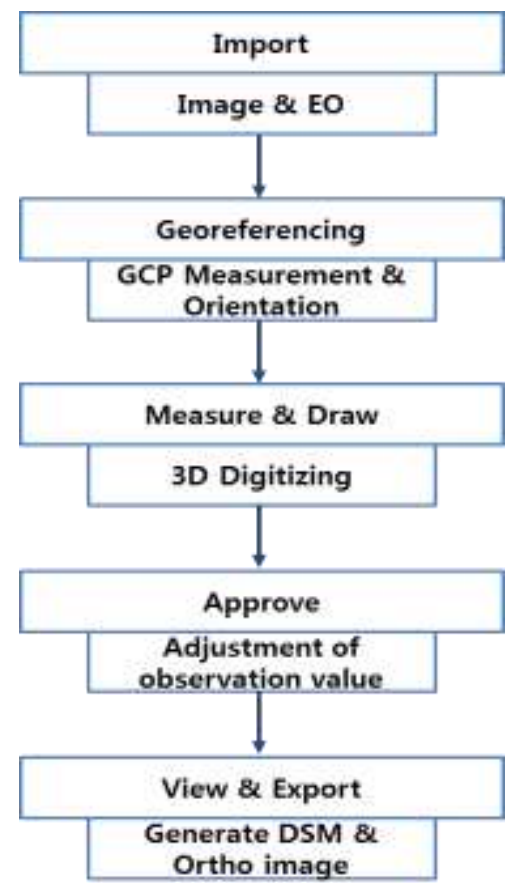

Figure 6. Steps of Data Processing

In the image import step, images and EO values are read and tie points are extracted. GCP measurement and orientation are performed in the georeferencing step. Normal UAV data processing software generates DSM and ortho images through this step. However, Datumate can perform 3D digitizing before DSM and ortho image generation. In the Measure and Draw step, user can measure points with 3D coordinates in a single oblique photo.

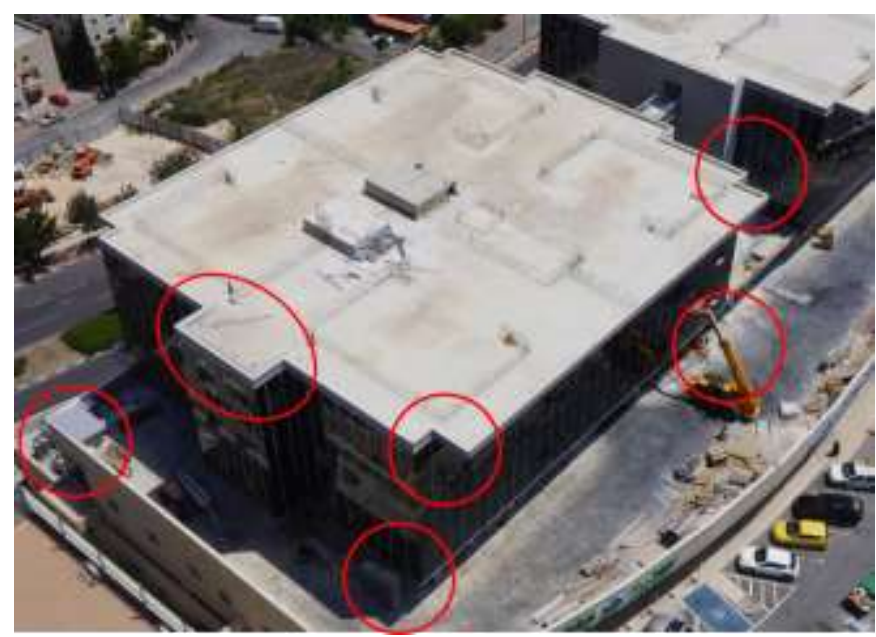

Figure 7. Oblique Photo

As shown in Figure 7 single photo is very effective for 3D digitizing because it is easier to measure corner points of buildings than ortho image. After georeferencing and 3D digitizing, the measured values are adjusted and finally DSM and ortho images can be created. 


\section{3D Digitizing and Volume Calculation}

This study performs the 3D digitizing and volume calculation of buildings using results generated via data processing. Figures 8 and 9 show DSM and ortho images.

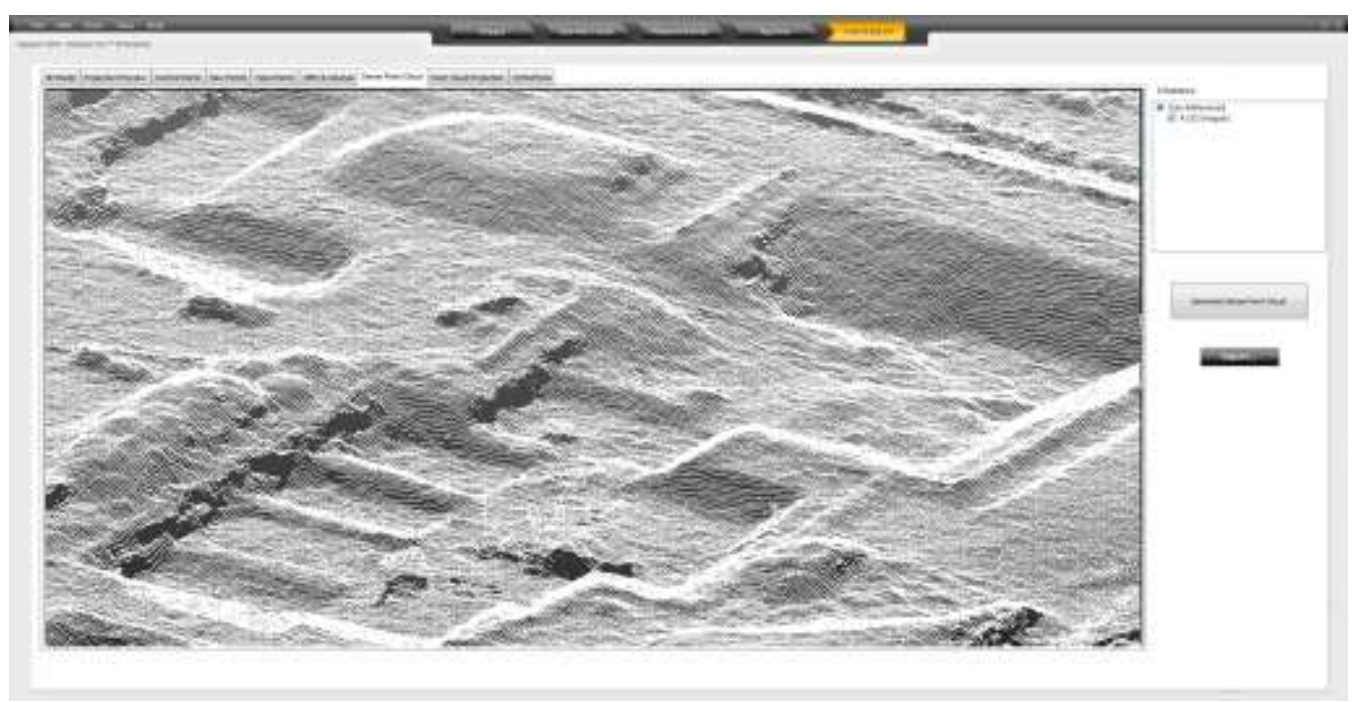

Figure 8. Digital Surface Model

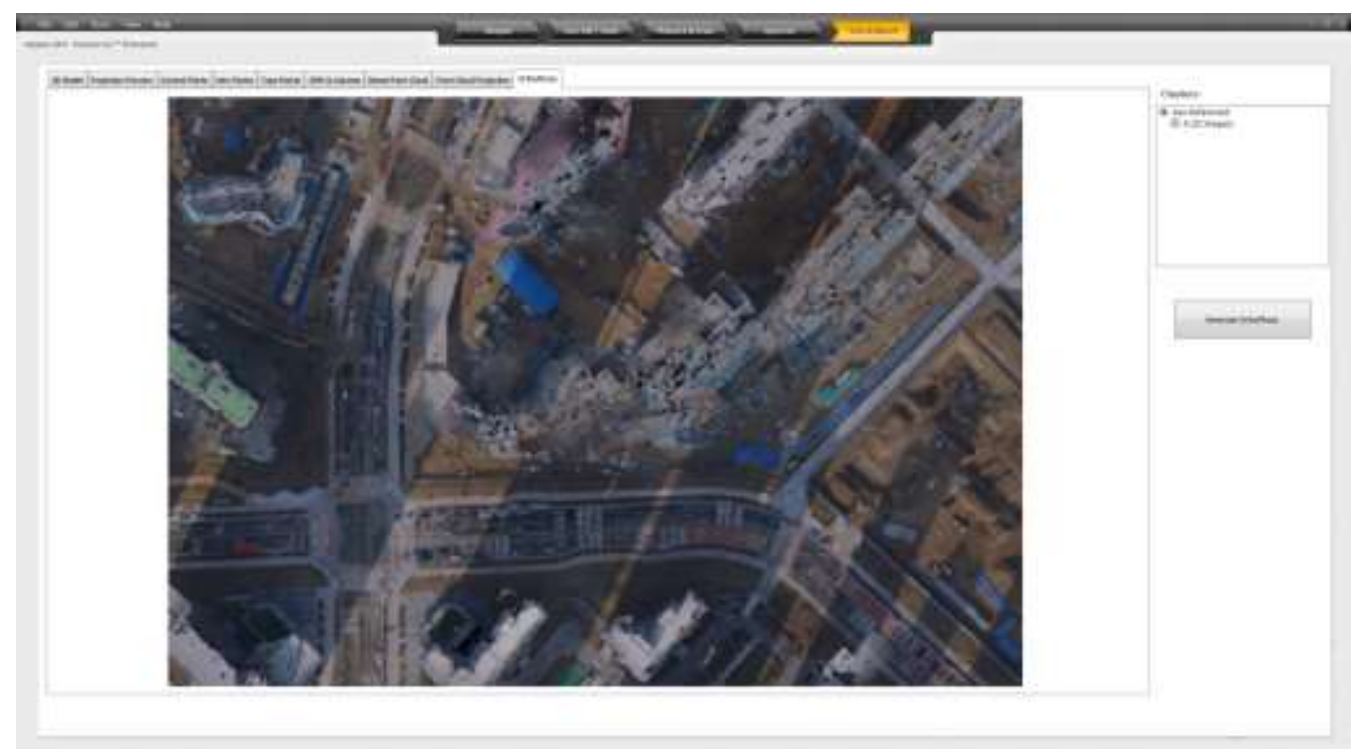

Figure 9. Ortho Image

The building of the study site was selected for 3D digitizing and its corner points and surrounding roads points were measured. The measured data has three-dimensional coordinates and can be used in CAD software. Figure 9 shows the 3D digitizing process of the building and Figure 10 shows the 3D digitizing data. 


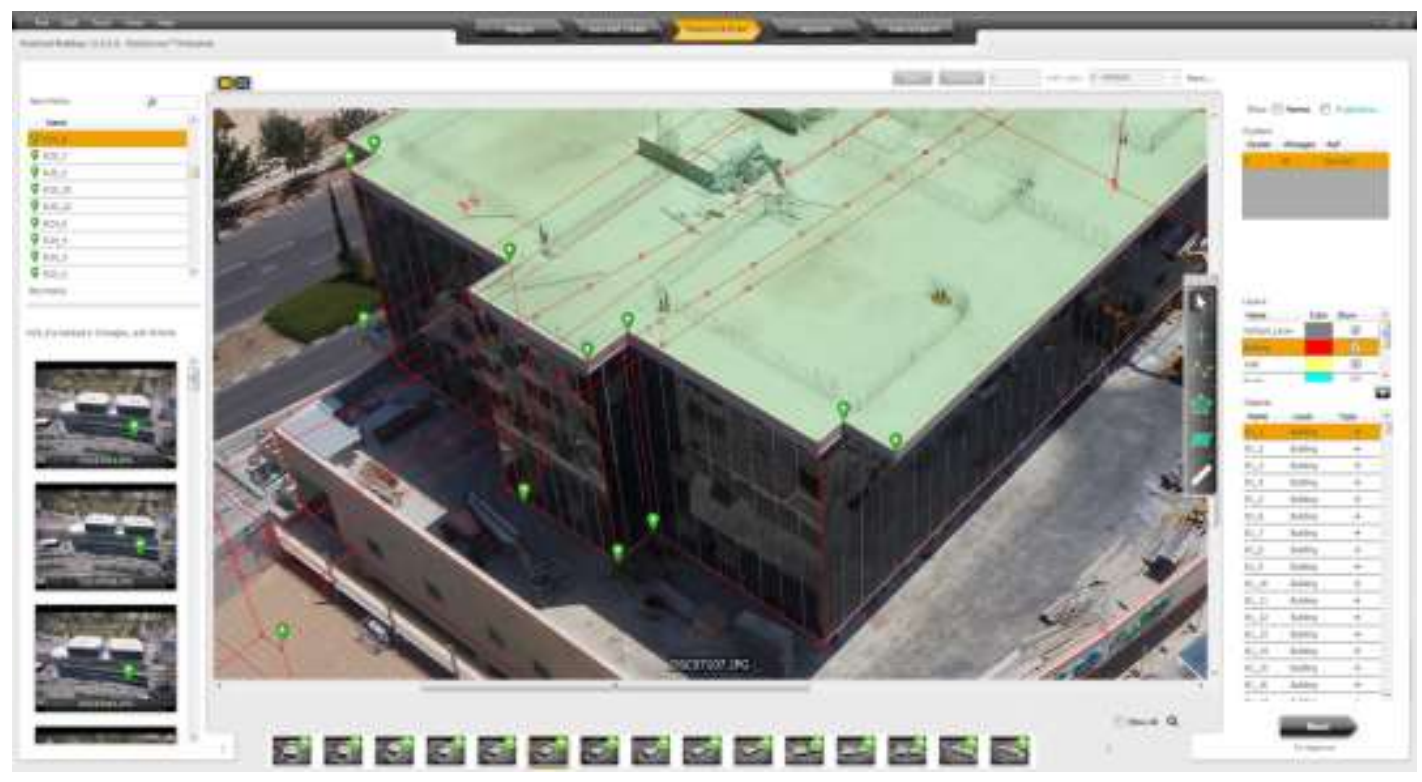

Figure 9. 3D Digitizing Process

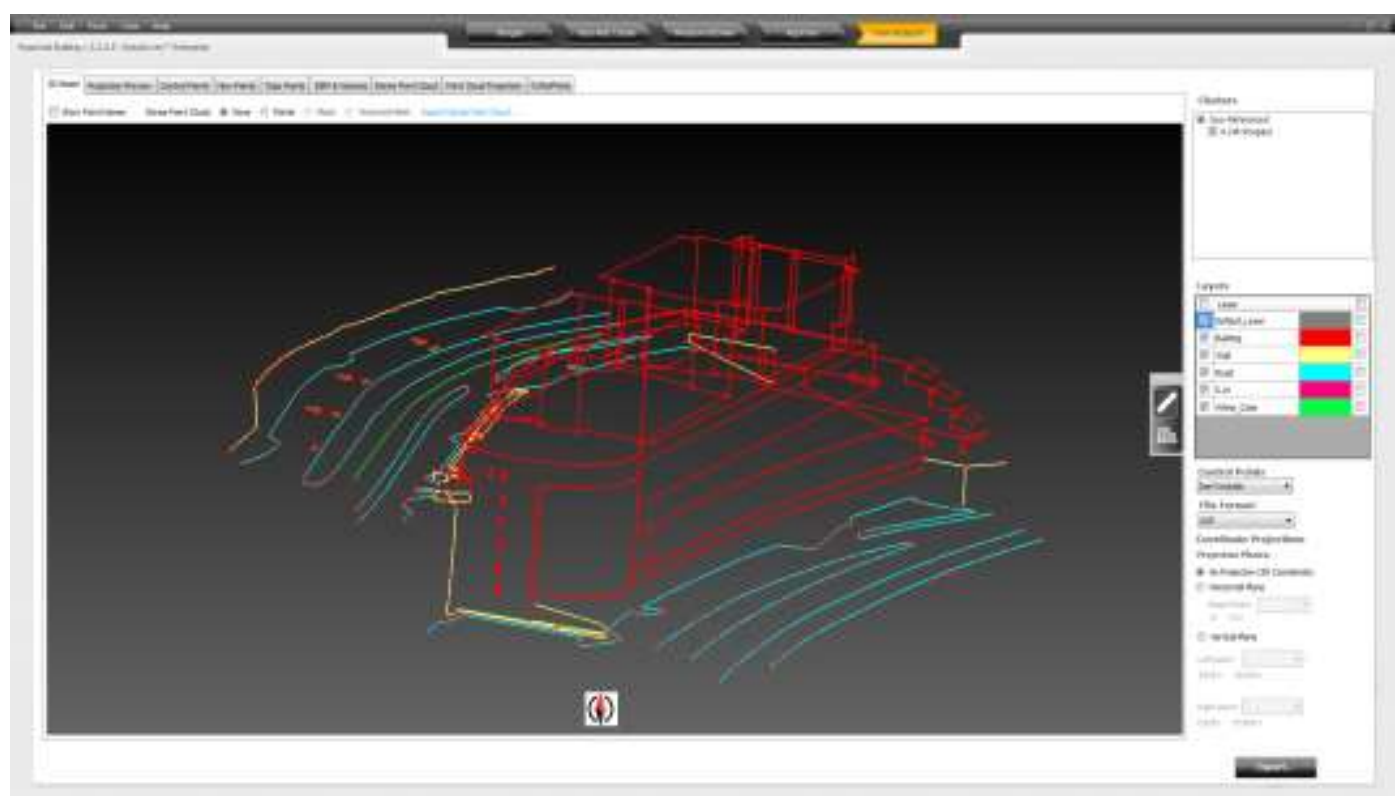

Figure 10. 3D Digitizing Data

3D digitizing data can be used in civil engineering software such as CAD, thus it can be used to model urban buildings. The 3D modeling of cities has recently been performed, and the method used in this study can greatly improve the efficiency of these tasks. In addition, the 3D digitizing data can be used in areas such as cartography, because it is possible to distinguish layers. The red line in Figure 11 is the building layer, the sky blue is the road, and the yellow is the wall. In this study, the earthwork volume of the study site was estimated using the DSM to show the application of UAV in a civil engineering project. Figure 12 shows the volume calculation screen. 


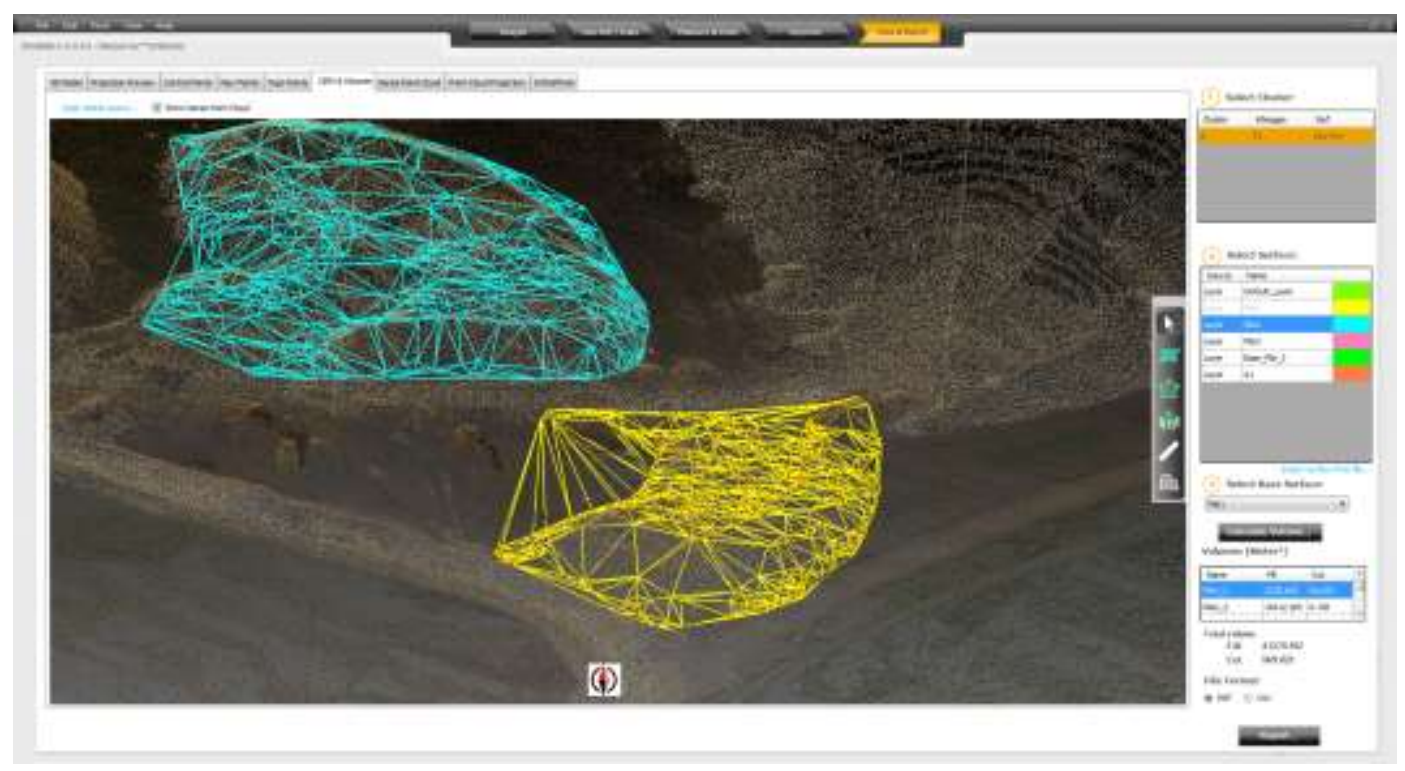

Figure 12. Volume Calculation

The volume was calculated by setting the reference cross section and using DSM. A reference section was created at $2 \mathrm{~m}$ from the ground, and the volumes for the fill and cut of the reference plane were calculated. The calculated fill was $41,275.912 \mathrm{~m}^{3}$ and the cut was $569.023 \mathrm{~m}^{3}$. Volume calculation using UAV data is faster than conventional survey methods and it can reduce the time required to acquire data.

\section{Conclusions}

In this study, data acquisition using UAV and 3D digitizing data were performed, and the following conclusions were obtained.

1. DSM and ortho images of a $300 \times 300 \mathrm{~m}$ area were generated through about 20 minutes of data acquisition and $3 \mathrm{D}$ digitizing and volume calculation were performed using the results.

2. 3D digitizing data using UAV is compatible with software widely used in civil engineering fields such as CAD, so it is very useful and can be used for mapping because it makes it possible to classify layers.

3. The calculation of volume using DSM data can greatly improve the efficiency of the work of estimating earth work because the quantity of fill and cut can be calculated through setting the reference plane.

\section{Acknowledgments}

This research was supported by Basic Science Research Program through the National Research Foundation of Korea(NRF) funded by the Ministry of Education, Science and Technology(No. NRF-2015R1A1A1A05001366)

\section{References}

[1] M. Chowdhury, D. Basak and P. P. Purohit, "Location-based Post Natural Disaster Warning and Evacuation System", Smart Computing Review, vol.4, no.6, (2014), pp.491-505.

[2] K. W. Lee, "Extraction of Road Information Based on High Resolution UAV Image Processing for Autonomous Driving Support", Journal of the Korea Academia-Industrial cooperation Society, vol.18, no.8, (2017), pp.335-360.

[3] K. W. Lee and J. K. Park, "Generation of 3D Drawing using Unmanned Aerial Vehicle Image", Proceedings of $4^{\text {th }}$ International Conference on GST 2017, (2017), pp.106-107. 
[4] J. K. Park and D. W. Park, "Availability Evaluation of Unmanned Aerial Vehicle for the Cadastral Confirmation Survey", International Journal of Applied Engineering Research, vol.10, no.18, (2015), pp.39163-39167.

[5] S. B. Lim, C. W. Seo and H. C. Yun, "Digital Map Updates with UAV Photogrammetric Methods", Journal of the Korean Society of Surveying, Geodesy, Photogrammetry and Cartography, vol.33, no.5, (2015), pp.397-405.

[6] Y. J. Kim, J. H. Oh and C. N. Lee, "Electric Power Line Dips Measurement Using Drone-based Photogrammetric Techniques", Journal of the Korean Society of Surveying, Geodesy, Photogrammetry and Cartography, vol.35, no.6, (2017), pp. 453-460.

[7] S. Hadim and N. Mohamed, "Middleware: middleware challenges and approaches for wireless sensor networks", IEEE Distributed Systems, vol. 7, no. 3, (2006), pp. 1-23.

[8] S. Park, S. D. Hong and H. S. Hong, "Technical Analysis of Unmaned Aircraft System using Revealed Patent Advantage and Patent Impact Index", Journal of the Korea Academia-Industrial cooperation Society, vol.11, no.8, (2010), pp.2835-2839.

[9] I. S. Lee, J. W. Lee, S. J. Kim and S. H. Hong, "Orthophoto accuracy assessment of ultra-light fixed wing UAV photogrammetry techniques", Journal of the Korean Society of Civil Engineers, vol.33, no.6, (2013), pp. 2593-2600.

[10] J. K. Park and M. G. Kim, "Application of unmanned aerial vehicle for detection of pine wilt disease", The Asian International Journal of Life Science, vol.10, (2014), pp.191-202.

[11] Y. S. Cho, N. Y. Lim, W. S. Joung, S. H. Jung and S. K. Choi, "Management of Construction Fields Information Using Low Altitude Close-range Aerial Images", Journal of the Korean Society of Surveying, Geodesy, Photogrammetry and Cartography, vol.32, no.5, (2014), pp.551-560.

[12] M. G. Kim and J. K. Park, "Assessment of Unmanned Aerial Vehicle for Management of Disaster", Information. Journal of the Korea Academia-Industrial cooperation Society, vol.16, no.1, (2015), pp.697-702.

[13] M. M. Wang, J. N. Cao, J. Li and S. K. Dasi, "Middleware for wireless sensor networks: A survey", Journal of Computer Science and Technology, vol. 23, no. 3, (2008), pp. 305-326.

[14] J. N. Kim and D. Y. Um, "High Quality Ortho-image Production Using the High Resolution DMCII Aerial Image", Journal of the Korean Society of Surveying, Geodesy, Photogrammetry and Cartography, vol.33, no.1, (2015), pp.11-21.

[15] J. K. Park and D. W. Park, "Availability Evaluation of Unmanned Aerial Vehicle for the Cadastral Confirmation Survey", International Journal of Applied Engineering Research, vol.10, no.18, (2015), pp.39163-39167.

[16] Digital Times, (2016), http://www.dt.co.kr/.

[17] Wirelessdictionary, (2016), http://www.wirelessdictionary.com/.

[18] Wonju enterprise city, (2017), http://www.wonjuec.co.kr/.

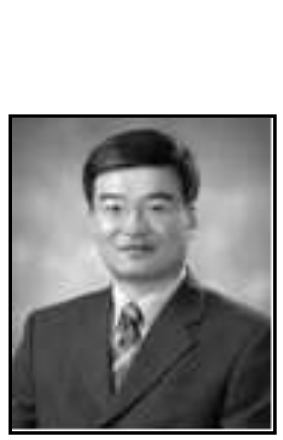

\section{Authors}

Keun-Wang Lee, he is currently a Professor in Department of Multimedia Science at Chungwoon University. He received his B.S., degree in Computer Engineering from Hanbat National University in 1993, M.S. and Ph.D. degree in Computer Science and Engineering from Soongsil University in 1996, 2000, respectively. His research interests are in the areas of Image Processing.

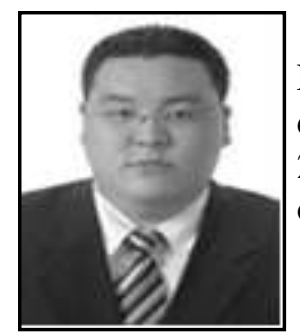

Joon-Kyu Park, he is currently a Professor in Department of Civil Engineering at Seoil University. He received his B.S., M.S. and Ph.D. degree in Civil Engineering from Chungnam National University in 2001, 2003, 2008, respectively. His research interests are in the areas of GPS, Geo-Spatial Information Engineering. 
International Journal of Advanced Science and Technology

Vol.112 (2018) 